\title{
New Model for Material Transportation to Improve Efficiency of Production Line
}

\author{
Mervat Badr ${ }^{1}$, Mahmoud Mohamed Ahmed Sayed ${ }^{2}$, Abd El Rohman Aref ${ }^{2}$, Abdallah Salah ${ }^{2}$ \\ ${ }^{1}$ Mechanical Engineering, Engineering Department, National Research Centre, Cairo, Egypt \\ ${ }^{2}$ Mechanical Engineering, Engineering Department, Canadian International College, Cairo, Egypt
}

Email address:

drmabadr@gmail.com (M. Badr), m_m_sayed@cic-cairo.com (M. M. A. Sayed)

\section{To cite this article:}

Mervat Badr, Mahmoud Mohamed Ahmed Sayed, Abd El Rohman Aref, Abdallah Salah. New Model for Material Transportation to Improve Efficiency of Production Line. International Journal of Science and Qualitative Analysis. Vol. 4, No. 2, 2018, pp. 60-64.

doi: $10.11648 /$ j.ijsqa.20180402.14

Received: April 25, 2018; Accepted: May 14, 2018; Published: May 29, 2018

\begin{abstract}
The objective of this study is to achieve higher efficiency in production operation through improving the material handling to minimize wastes represented in delivery delay or work in process (WIP) inventory. It is suggested that material is transferred from the warehouse using a tug train system. Advanced tools are required in collecting data of the station inputs to construct an optimum schedule for the train. A new model for material transportation that applies "shortest processing time" (SPT) sequencing rule is proposed. A simulation model was developed; using programming language designed for Simul8 software, for the sake of validating the proposed transportation model. The number of bins delivered to each working station is limited by the demand of each station and its maximum side line inventory. The simulation model is applied on a case study, washing machine production line of "Electrolux" factory in Egypt. The results of the simulation model are found to be similar to the results obtained from the transportation model that was applied using SPT sequencing rule. This work is applied only on the inputs to the stations.
\end{abstract}

Keywords: Material Flow, Mixed-Line Production, Simulation, Tug Train

\section{Introduction}

Several researches conducted in the field of production planning were concerning mixed-line production. The mixed-model assembly line helps in meeting variable demand on different types of products that have no major changes in design and are produced in small batches.

Tiacci, [1] presented an "event and object oriented" simulation model for assembly lines. The simulator is developed in JAVA and is capable to simulate mixed model assembly lines, with stochastic task times, parallel stations, fixed scheduling sequences, and buffers within workstations. The attained output is the throughput of a complex line while the inputs are three arrays that represent: line configuration (number of workcentres, line side inventory space of each of them, tasks assigned to each workcentre and number of parallel workstations in each workcentre) in addition to the sequence of models entering the line.

Hsiang-Hsi Huang et al. [2], focused on resolving the bottleneck problem developing a mechanism based on "theory of constraints" (TOC). A case study of TFT-LCD was presented as an illustration of the developed mechanism. The results showed an increase in production flexibility and manufacturing system mobility. The authors used: "earliest due date" (EDD) and "drum buffer rope" (DBR) scheduling methods using the due date as main performance index. Simulation software package (Flexsim) was used to evaluate the system performance. In our current work "shortest processing time" (SPT) is the applied scheduling rule andSimul8 software package is used for developing the simulation program targeting efficient use of the spaces around every station as a line side inventory.

Some researchers proposed the use of tug trains for material flow in mixed model assembly lines (MMAL). They also suggested that the train is moving based on in-plant milk run. To plan such system, train routing, scheduling, and loading must be determined, [3]. In their research argued four decisions were considered; supermarkets number and locations, number of tow trains, train's fixed schedule and the loaded bins 
for each tour. The methodology adopted in their study was based on dynamic programming (DP) and mixed integer programming (MIP). To demonstrate the methodology it was applied on a case of 20 stations supplied by required parts using tug trains. To overcome the bottleneck problem; in the same time decreasing both the number of trains and system variability, early loading of bins is used.

As automobiles are produced through mixed-model assembly lines (MMAL), most of automobile producers are now adopting decentralized in-house storage in what is called supermarkets to ensure flexible and reliable Just-in-Time (JIT) part supply. The parts are stored and loaded using small tow trains. To aid reliable parts supply, it was necessary to solve the interdependent problems of routing and scheduling which is considered as an important optimization problem. Hence, an exact solution procedure which solves both problems simultaneously in polynomial runtime was proposed by Emde and Boysen, [4]. Trade-off between number and capacity of tow-trains and side line inventory of each station were investigated within a comprehensive computational study.

In their study Alnahhal and Noche, [5] to investigate tugger train routing, scheduling, and loading problems in an unsteady environment they presented an approach for dynamic material flow control that is based on handling unexpected fluctuations in stations demand through handling their causes such as machine breakdown, etc. A mix between the demand-oriented and electronic kanban systems was used. Fixed routing and early loading were assumed to reduce the complication of planning process and compensate the sudden increase in demand. The objectives considered are minimizing the possibility of early loading, number of train cycles, and the deviations from the ideal safety stock size. They concluded that the presented approach outperforms the kanban system.

Goulda et-al, applied material flow assessment framework to a complex multi-product and multi-site manufacturing system with a case study demonstration [6]. While Liua et-al developed a new performance indicator for material flow effectiveness in production systems, validating the usefulness of this indicator through a simulation study on a machining equipment manufacturing company in Taiwan, [7]. The buffer management and the DBR scheduling methods based on the Theory of Constraints were used to identify, the level of bottleneck problems in the system to increase the production flexibility using "Flexsim" simulation software,
[8]. A multi-objective ant colony optimization (MOACO) algorithm is proposed here to minimize the number of stations for a given cycle time, [9].

\section{Study Objectives and Method}

The objectives of this study are; minimizing the routing time of the train, minimizing the costs of holding inventory at each station, and to prevent the bottleneck at each station during system variations. Hence, two main aspects; scheduling and loading are investigated together. During working these problems there are some constraints to be taken into consideration such as; tug train capacity and lineside inventory limit.

As an example the following case is considered using the same assumptions about the deterministic nature of demand of parts and processing times. There are 5 stations supplied by parts using tug trains. The 5 stations are assumed to assemble only 14 types of product models. Table 1 exhibits the parts needed by each station. It is assumed here that each station needs different types of parts for all the five stations. However, the parts are different from one station to another.

Table 1. Different types of demand for the five stations.

\begin{tabular}{ll}
\hline Inputs from the warehouse to the stations & Station \\
\hline $\mathrm{X}_{1}:$ Carborane & \\
$\mathrm{X}_{2}:$ Hub 22 & $\mathrm{~S}_{1}$ : Injection station \\
$\mathrm{X}_{3}:$ Hub 20 & \\
$\mathrm{X}_{4}:$ sheet metal for the washer cabin & \\
$\mathrm{X}_{5-1}:$ front flange & $\mathrm{S}_{2}$ : Press line \\
$\mathrm{X}_{5-2}:$ back flange & \\
$\mathrm{X}_{6-1}:$ drum cover $22 \mathrm{~mm}$ & \\
$\mathrm{X}_{6-2}:$ drum cover $20 \mathrm{~mm}$ & \\
$\mathrm{X}_{7-1}:$ big fins & $\mathrm{S}_{3}:$ Stainless drum \\
$\mathrm{X}_{7-2}:$ small fins & line \\
$\mathrm{X}_{8-1}:$ star $1200 \mathrm{rpm}$ & \\
$\mathrm{X}_{8-2}:$ Star $1000 \mathrm{rpm}$ & \\
$\mathrm{X}_{8-3}:$ Star 800 rpm & \\
$\mathrm{X}_{9}:$ big back of the washer & \\
$\mathrm{X}_{10}:$ right truss & \\
$\mathrm{X}_{11}:$ left truss & \\
$\mathrm{X}_{12-1}:$ Chemicals(Axe-Nobel Powder) "White" & \\
$\mathrm{X}_{12-2}:$ Chemicals(Axe-Nobel Powder) "Silver" & \\
$\mathrm{X}_{13}:$ Small Back of The Washer & $\mathrm{S}_{5}:$ Painting line \\
\hline
\end{tabular}

There is a variation in demand between the stations and the warehouse as shown in Table 2.

Table 2. Variability in demand for different stations per shift.

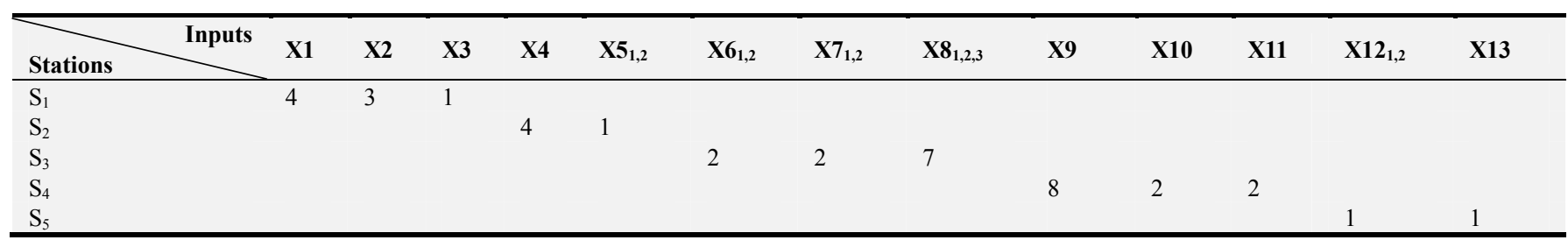

\subsection{Route Length Determination}

To find the period length for each group of stations supplied by the same train, at first the minimum number of routes (cycles) of the train per shift from the warehouse to the five stations is computed based upon the demand per 
station and the train capacity [4].

$$
\begin{aligned}
& \operatorname{MNR}(\mathrm{W}, \mathrm{S})=\frac{\text { Shift Demand Per Stations }}{\text { Train Capacity }} \\
& =\frac{38}{4}=9.5 \text { routes (approximately } 10 \text { routes) }
\end{aligned}
$$

The Maximum Period Length, MAXPL from the warehouse to the stations can be estimated using this equation, [4]:

$$
\begin{gathered}
\operatorname{MAPL}(\mathrm{W}, \mathrm{S})=\frac{\text { Number of Cycle inThe Shift }}{\text { Minimum Number of Routes }(\operatorname{MNR}(\mathrm{si}, \mathrm{sj}))} \\
=\frac{8 \times 60 \text { minutes }}{9.5}=50 \text { minutes per route }
\end{gathered}
$$

Where the minimum period length of the train is based upon observations of the routing time inside the stations, the routing time outside the stations and the time of unloading materials, which equals 40 minutes, the following equation illustrates the minimum period length of the train, [4].

$$
\operatorname{MNPL}(\mathrm{W}, \mathrm{S})=\operatorname{RTI}\left(\mathrm{S}_{\mathrm{i}}, \mathrm{S}_{\mathrm{j}}\right)+\mathrm{RTOC}+\text { Time Buffer }
$$

Recording the total time; beginning from loading operation in the warehouse to unloading at the station, it was found to be 40 minutes; this indicates that if the train is traveling from the warehouse to cover the demand of one station, it takes 40 minutes / cycle.

Therefore the average route length of the train:

$$
\begin{aligned}
\operatorname{APL}(\mathrm{W}, \mathrm{S}) & =\frac{\operatorname{MAPL}(s i, s j)+\operatorname{MIPL}(\mathrm{si.sj})}{2} \\
& =\frac{50+40}{2}=45 \text { minutes per route }
\end{aligned}
$$

Materials Distribution Plan

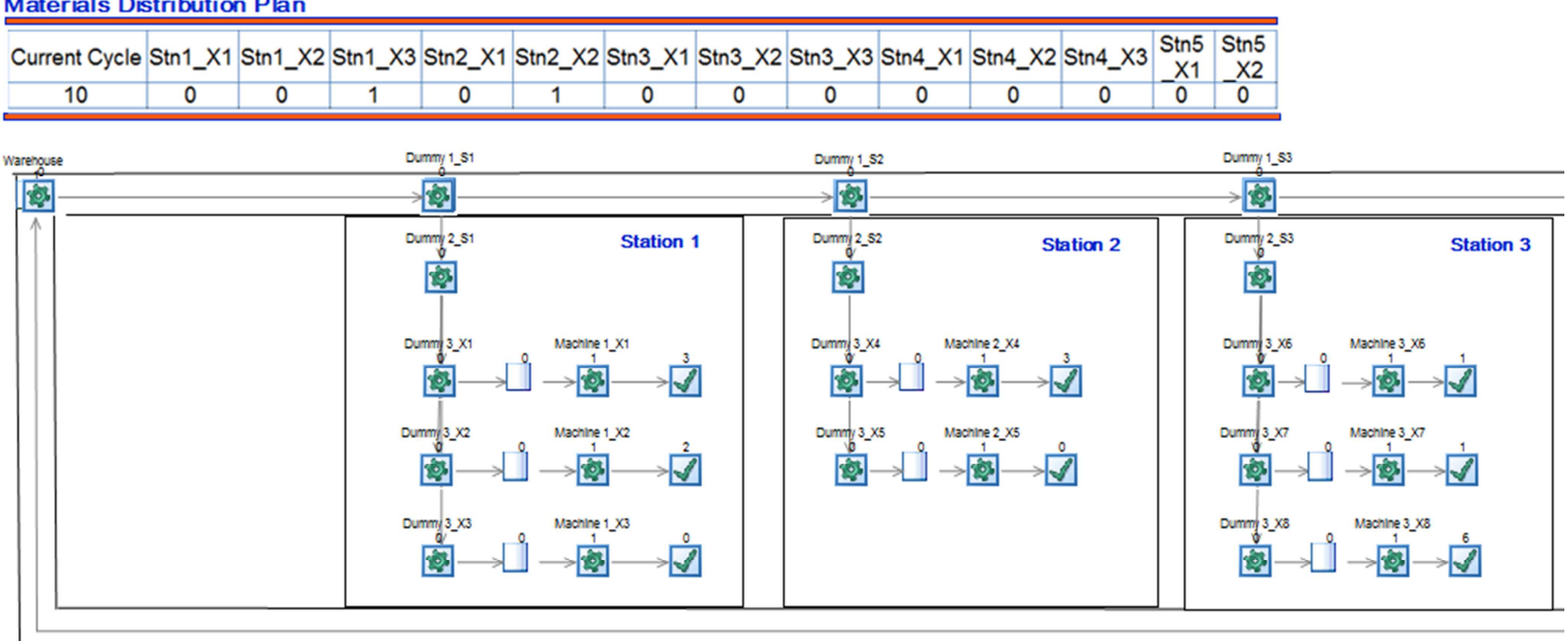

Figure 1. The simulation model of the five stations.

\section{Results and Discussions}

Figure 2, exhibits the optimum train schedule for the 10 cycles per shift. This schedule is obtained; applying SPT sequencing rule as it was mentioned above, to define the priority of demand among the 13 different types of parts

\subsection{The New Transportation Techniques Based Upon SPT Scheduling Rule}

According to the policy of the Electrolux company a schedule for the tug train is proposed and the average route length (cycle) is determined. Linear programming method is used to formulate a mathematical model for scheduling of the tug train. The proposed schedule is based on transportation technique, however the traditional methods such as "north west", "least cost" and "Vogel's approximation" [10], were found to be not appropriate to solve this case. A new procedure of transportation based on Sequencing Rules [11]; such as "Shortest Processing Time" and "Maximum Line Side Inventory"; that dynamically changes over time, is used for scheduling each cycle.

Using "shortest processing time" (SPT) to define the priority of demand among the 13 different types of parts supplied to the five stations; taking into consideration the maximum train capacity and the average cycle time calculated using the above mentioned equations. The maximum number of bins allowed in the side line inventory is defined from the actual permissible space around each station in the production line.

\subsection{Simulation of the Delivery Schedule}

Using simul8 simulation package, the tug train cycles are simulated to validate the obtained delivery schedule. Figure (1) shows the simulation model of the five stations as illustrated by simul8 package, using the package adopted language $(\mathrm{C}++)$. 
the technological area prevents starving of the stations, the last cycle of the train deliver the raw material from the warehouse to the stations to be dispatched for the next day (Housekeeping mode), the transferred number of bins from the warehouse to the five stations is verified with the transferred number of bins in the following simulation model.

\begin{tabular}{|c|c|c|c|c|c|c|c|c|c|c|c|c|c|c|c|c|c|c|c|c|c|c|c|c|c|c|c|c|c|}
\hline & \multicolumn{28}{|c|}{ Demand } & \multirow[b]{2}{*}{$\begin{array}{l}\text { Availability } \\
\text { (Train } \\
\text { capacity) }\end{array}$} \\
\hline $\begin{array}{l}\text { Source } \\
\text { (Cycles) }\end{array}$ & \multicolumn{2}{|c|}{$\begin{array}{l}\text { S1- } \\
\text { X1 }\end{array}$} & \multicolumn{2}{|c|}{$\begin{array}{l}\text { S1- } \\
\text { X2 }\end{array}$} & \multicolumn{2}{|c|}{$\begin{array}{l}\text { S1- } \\
\text { X3 }\end{array}$} & \multicolumn{2}{|c|}{$\begin{array}{l}\text { S2- } \\
\text { X4 }\end{array}$} & \multicolumn{2}{|c|}{$\begin{array}{l}\text { S2- } \\
\mathrm{X} 5\end{array}$} & \multicolumn{2}{|c|}{$\begin{array}{l}\text { S3- } \\
\text { X6 }\end{array}$} & \multicolumn{2}{|c|}{$\begin{array}{l}\text { S3- } \\
\text { X7 }\end{array}$} & \multicolumn{2}{|c|}{$\begin{array}{l}\text { S3- } \\
\text { X8 }\end{array}$} & \multicolumn{2}{|c|}{$\begin{array}{l}\text { S4- } \\
\times 9\end{array}$} & \multicolumn{2}{|c|}{$\begin{array}{l}\text { S4- } \\
\times 10\end{array}$} & \multicolumn{2}{|c|}{ S4-X11 } & \multicolumn{2}{|c|}{ S5-X12 } & \multicolumn{2}{|c|}{ S5-X13 } & \multicolumn{2}{|c|}{ Dummy } & \\
\hline \multirow[t]{2}{*}{ C1 } & \multicolumn{2}{|c|}{1} & & & & & \multicolumn{2}{|c|}{1} & & & & & & & \multicolumn{2}{|c|}{1} & \multicolumn{2}{|c|}{1} & & & & & & & & & & & \multirow{2}{*}{4} \\
\hline & 3 & 2 & 3 & 2.6 & 3 & 8 & 2 & 2 & 3 & 8 & 2 & 4 & 2 & 4 & 3 & 1.4 & 2 & 1 & 1 & 4 & 1 & 4 & 1 & 8 & 1 & 8 & 0 & 0 & \\
\hline$C 2$ & 1 & & & & & & 1 & & & & & & & & & & & & & & & & & & & & & & 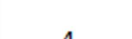 \\
\hline & 2 & 2 & 3 & 2.6 & 3 & 8 & 1 & 2 & 3 & 8 & 2 & 4 & 2 & 4 & 2 & 1.4 & 1 & 1 & 1 & 4 & 1 & 4 & 1 & 8 & 1 & 8 & 0 & 0 & \\
\hline $\mathrm{C} 3$ & 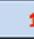 & & & 1 & & & & & & & & & & & & & & & & & & & & & & & & & \\
\hline & 1 & 2 & 3 & 2.6 & 3 & 8 & 0 & 2 & 3 & 8 & 2 & 4 & 2 & 4 & 2 & 1.4 & 1 & 1 & 1 & 4 & 1 & 4 & 1 & 8 & 1 & 8 & 0 & 0 & 7 \\
\hline $\mathrm{C4}$ & & & & 1 & & & 1 & & & & & & & & & & & & & & & & & & & & & & \\
\hline & 1 & 2 & 2 & 2.6 & 3 & 8 & 1 & 2 & 3 & 8 & 2 & 4 & 2 & 4 & 2 & 1.4 & 1 & 1 & 1 & 4 & 1 & 4 & 1 & 8 & 1 & 8 & 0 & 0 & 4 \\
\hline C5 & & & & & & & & & & & 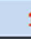 & & 1 & & & & & & & & & & & & & & & & A \\
\hline & 2 & 2 & 1 & 2.6 & 3 & 8 & 1 & 2 & 3 & 8 & 2 & 4 & 2 & 4 & 2 & 1.4 & 1 & 1 & 1 & 4 & 1 & 4 & 1 & 8 & 1 & 8 & 0 & 0 & 4 \\
\hline C6 & & & & & & & & & & & & & & & & & & 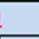 & 1 & & 1 & & & & & & & & \\
\hline & 3 & 2 & 1 & 2.6 & 3 & 8 & 1 & 2 & 3 & 8 & 1 & 4 & 1 & 4 & 2 & 1.4 & 1 & 1 & 1 & 4 & 1 & 4 & 1 & 8 & 1 & 8 & 0 & 0 & 4 \\
\hline C7 & 1 & & & & & & 1 & & & & & & & & & & & & & & & & & & & & & & \\
\hline & 3 & 2 & 2 & 2.6 & 3 & 8 & 2 & 2 & 3 & 8 & 2 & 4 & 2 & 4 & 2 & 1.4 & 1 & 1 & 1 & 4 & 1 & 4 & 1 & 8 & 1 & 8 & 0 & 0 & \\
\hline C8 & & & & 1 & & & & & & & 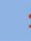 & & 1 & & & & & & & & & & & & & & & & \\
\hline & 2 & 2 & 3 & 2.6 & 3 & 8 & 2 & 2 & 3 & 8 & 2 & 4 & 2 & 4 & 2 & 1.4 & 1 & 1 & 1 & 4 & 1 & 4 & 1 & 8 & 1 & 8 & 0 & 0 & \\
\hline C9 & & & & & & & & & & & & & & & & & & & 1 & & 1 & & 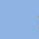 & & 1 & & & & 4 \\
\hline & 2 & 2 & 2 & 2.6 & 3 & 8 & 1 & 2 & 3 & 8 & 1 & 4 & 1 & 4 & 3 & 1.4 & 2 & 1 & 0 & 4 & 0 & 4 & 0 & 8 & 0 & 8 & 0 & 0 & \\
\hline C10 & & & & & & & & & & & & & & & & & & & & & & & & & & & & & \\
\hline & 3 & 2 & 2 & 2.6 & 3 & 8 & 2 & 2 & 3 & 8 & 1 & 4 & 1 & 4 & 1 & 1,4 & 2 & 1 & 0 & 4 & 0 & 4 & 0 & 4 & 0 & 4 & 0 & 0 & 4 \\
\hline Dem & 3 & & & 2 & & & 3 & & 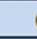 & & 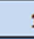 & & 1 & & & & & 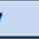 & 1 & & 1 & & 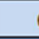 & & 0 & & & & \\
\hline$U$ & 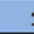 & & & 1 & . & & 1 & & 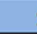 & & 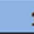 & & 1 & & & & & & 1 & & 1 & & 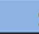 & & 1 & & & & \\
\hline
\end{tabular}

Figure 2. The optimum schedule train for the 10 cycles per shift.

A sample of the results of applying the developed delivery system simulation model is shown in figure 3.

Materials Distribution Plan

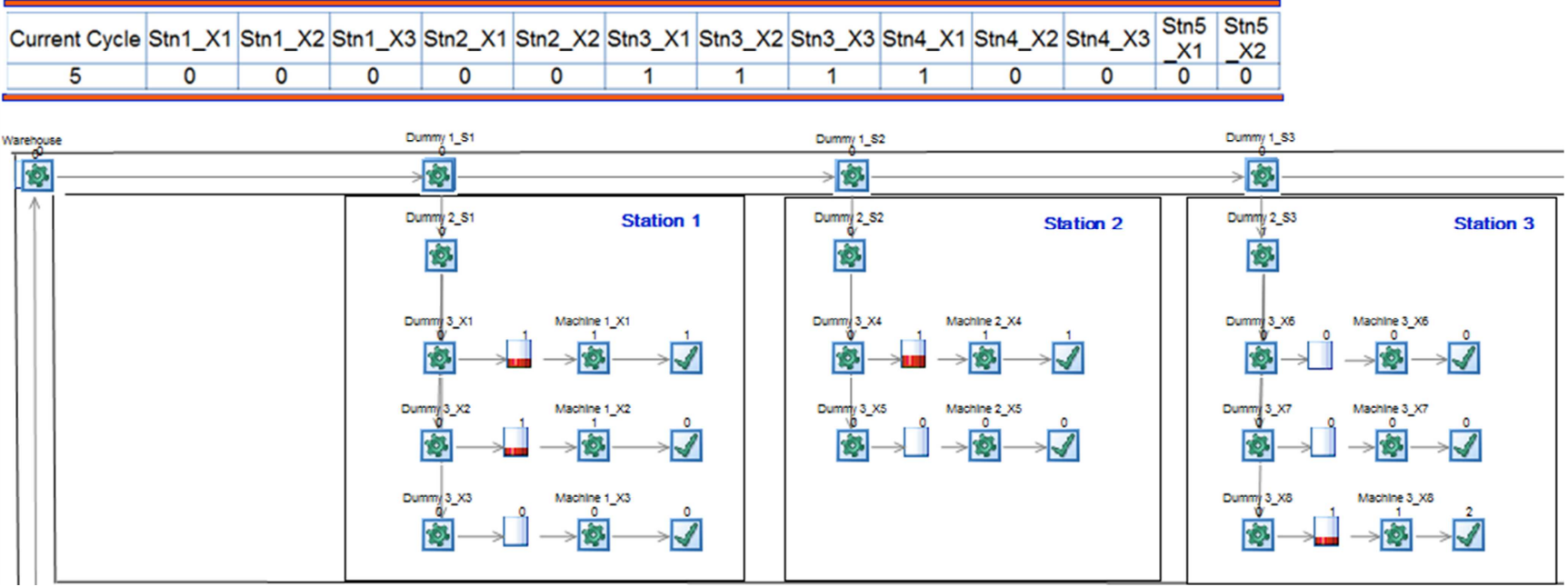

Notes: Icon $\rightarrow$ is interpreted as the demand at this station is 3 bins

Figure 3. Results of one of delivery system simulation runs. 
In Figure 3, it is noticed that for station (1) the demand of part $\left(\mathrm{X}_{1}\right)$ is 3 bins; as explained above. While there is one bin in the side line inventory (red area at the bottom of the storage bin) as an early loading for the next day. This indicates that simulation result is in agreement with the results obtained of the delivery schedule (Table 1) that exhibits the results of applying the transportation technique and shortest processing time (SPT), from the simulation results it is seen that:

(i) The waiting time for the bins of the raw materials $\left(X_{1}\right.$, $\mathrm{X}_{4}$ ) is high compared to the other raw materials, where the line side inventory for the items $\left(\mathrm{X}_{7}, \mathrm{X}_{8}\right)$ is very utilized compared to the other line side inventory for different items. The idle time for machine working on items $\left(\mathrm{X}_{2}\right)$ is very high compared to the other machines, while the idle time for the other machines is $10 \%$ per the total time of the shift, utilized $90 \%$.

(ii) The average time of the waiting and processed time for the four bins entering the machine number one is nearly equal to average time of the other bins entering other machines, therefore the idle and utilized time for each machine is nearly equal. The standard deviation for the work exit point at each machine indicates that the rate of exiting the bin from each station isn't constant.

(iii) The forklift is Hired from another Company with Cost $=40 \mathrm{LE} /$ Hour

Therefore the Cost per Day $=40 \times 9=360$ LE, i.e. 1800 LE/Week $=7200$ LE/ Month.

Hence, the total cost per Year amounts to $86400 \mathrm{LE} /$ Year.

This means that Free Factory Forklift will eliminate 86400 LE/Year. The tug train is more safety than the forklift during the transportation of the raw materials from the warehouse to the five stations in the technological area.

\section{Conclusions}

This research is a trial to reach a situation of zero forklifts in the technological area of a factory that consists of different products, mixed-model assembly lines. Also, it is drawn from the developed transportation schedule and simulation model. The newly delivery system of the raw materials from the warehouse to the five stations in the technological area prevents starving of the stations, reduces time of transportation and improves productivity. In case of changeover (changing from one product to another) the tug train schedule is built based on electronic Kanban system. Verification of the results, as the simulation model indicates that the efficiency of the tug train delivery system is higher than the efficiency of the forklift using simul8 software package. Also, to fully eliminate the motion of the forklift in the technological area, the Structural Work-In-Process inventory must be decrease to a certain limit.

\section{Appendix}

Illustration of some of frequently used icons in simul8 software package

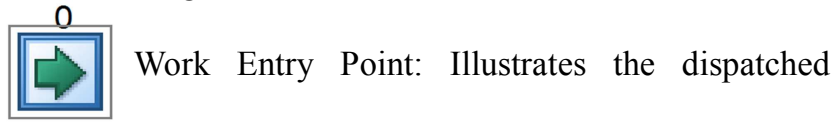

number of bins

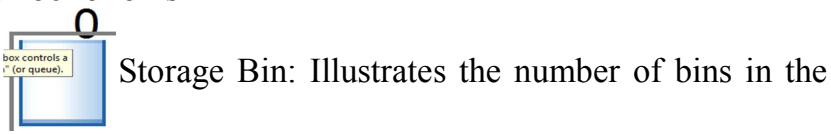

line side inventory

Wo

\section{References}

[1] Lorenzo Tiacci, "Event and object oriented simulation to fast evaluate operational objectives of mixed model assembly lines problems", Simulation Modeling Practice and Theory 24 (2012) 35-48

[2] Hsiang-Hsi Huang, Wen Pei, Horng-Huei Wu, Ming-Der May, "A research on problems of mixed-line production and the rescheduling", Robotics and Computer-Integrated Manufacturing 29 (2013) 64-72

[3] Simon Emde Nils Boysen, "Optimally locating in-house logistics areas to facilitate JIT-supply of mixed-model assembly lines", Int. J. Production Economics 135 (2012) 393-402

[4] Simon Emde, Nils Boysen, "Optimally routing and scheduling tow trains for JIT-supply of mixed-model assembly lines", European Journal of Operational Research 217 (2012) 287299

[5] Mohammed Alnahhal, Bernd Noche, "Dynamic material flow control in mixed model assembly lines", Computers \& Industrial Engineering 85 (2015) 110-119.

[6] Oliver Goulda, Alessandro Simeone, James Colwill, Roy Willeyb, Shahin Rahimifarda, "A material flow modeling tool for resource efficient production planning in multi-product manufacturing systems". Procedia CIRP 41 (2016) $21-26$.

[7] Chi-Shuan Liua, Luo-Yan Lina, Ming-Chih Chenb, HorngChyi Hornga, "A New Performance Indicator of Material Flow for Production Systems”. Procedia Manufacturing 11 (2017) $1774-1781$

[8] Hsiang-Hsi Huang, Wen Pei, Horng-Huei Wu, Ming-Der May, "A research on problems of mixed-line production and the rescheduling". Robotics and Computer-Integrated Manufacturing 29 (2013) 64-72

[9] Betul Yagmahan, "Mixed-model assembly line balancing using a multi-objective ant colony optimization approach". Expert Systems with Applications 38 (2011) 12453-12461

[10] Prem Kumar Gupta, "operations research", S. Chand, 1999

[11] R. Dan Reid, Nada R. Sanders, "Operations Management: An Integrated Approach", Fourth Edition, John Wiley \& Sons, Inc., 2011. 